\title{
DE LA JUNGLA DE LAUTRÉAMONT A SELVA MÁRQUEZ: EL (CASI) INEXISTENTE SURREALISMO URUGUAYO
}

\author{
POR \\ EDUARDO ESPINA \\ Texas A \& $M$ University
}

La ausencia en la literatura uruguaya del influjo de la estética surrealista como alternativa inquietante y distintiva parece una incongruencia difícil de explicar a primera vista, aún más teniendo en cuenta la resonancia que este tipo de propuesta vital y artística tuvo en grupos tan seminales como "La mandrágora" en Chile y el que circuló alrededor de la revista Qué en Argentina, países con los cuales el Uruguay ha mantenido un intercamabioliterario de manera reincidente. Lo cierto es que en la tierra de Lautréamont el surrealismo pasó desapercibido. La paradoja, en un país que se ha vanagloriado de su afrancesamiento, es de por sí surrealista. Es casi imposible rastrear huellas y encontrar excepciones, aunque las hay. Puede concluirse sin mayor reparo que no hubo revistas vinculadas al movimiento fundado por André Breton; tampoco hay constancia de que algún determinado grupo interesado en la actualización de la poesía haya tenido una actividad surrealista pública. Como si fuera poco, ni siquiera ha habido claridad en el discurso crítico nacional para definir el término en cuestión, lo cual llevó a considerar erróneamente la vinculación de algunos escritores con el surrealismo, cuando en verdad muy ajenos estuvieron a toda gimnasia intelectual propendiente a descifrar y promulgar la actividad del inconsciente. Mientras que al otro lado del Río de la Plata se fundaba en 1927 el primer grupo surrealista de América Latina, inmediatamente después de su gran eclosión en Francia, el otro margen del ancho río como mar -la orilla izquierda - el más subversivo de los movimientos literarios de este siglo pasaba inadvertido en los cenáculos literarios y pictóricos, todavía sin despertar a los acechos del nuevo tiempo. Con la imponente figura egregia de Joaquín Torres García, cuya práctica metódica y constructivista pareció un catalizador difícil de evitar, puede entenderse la falta de toda propensión al delirio en las artes plásticas uruguayas. Las traducciones de lo visual estuvieron más cerca de la razón que del exceso: el ojo nunca llegó a apropiarse de la percepción ni el orden de la realidad llegó a ser pulverizado por las pulsiones de lo imaginario. En poesía las cosas tendrian que haber sido diferentes de lo que fueron: más atrevidas y con un espacio para la subversión mucho más amplio. ¿Por qué la timidez es el signo que caracteriza a la lírica uruguaya? ¿Por qué la transgresión 
ha sido discontinua y el apego a las normatividades tan verificable en la inmensa mayoría de las obras? Algunas observaciones siguen inmediatamente, quizás anticipando la sinopsis que pueda responder a estas varias interrogantes. Como primera medida conviene recordar que las expresiones de ruptura en el Uruguay siempre han sido individuales y todavía más, inaugurándose contra el rechazo ideológico y estético del contexto social. El país posee una envidiable lista de raros de difícil acomodamiento social. La historia, que además de abundar en paradojas es la más grande de todas, vio nacer en la nación que más rechazó al surrealismo a dos de sus fundadores avant la lettre, uno escribiendo en francés y el otro en español. A Isidore Ducasse nunca se le reconoció carta de ciudadanía porque escribió en un idioma extranjero, por más que el fascinante conde se hiciera llamar "el montevideano" y nunca sintiera por Francia una preferencia definitiva, como las recientes investigaciones lo prueban. Fue desterrado de la literatura uruguaya por razones lingüísticas. Lo mismo puede decirse de Jules Laforgue y Jules Supervielle, poetas uruguayos por más que no escribieran en español ni fueran representantes ortodoxos de las costumbres literarias de la época. Casi ingenuamente podría preguntarse, ¿es menos irlandés Samuel Beckett porque escribió en francés, o dejó de ser ruso Vladimir Nabokov cuando escribió en inglés The Real Life of Sebastian Knight? César Moro escribió en francés y no obstante los peruanos, además de traducirlo, lo tienen como uno de sus poetas nacionales y como el primer surrealista descendiente de los incas. Lautréamont estableció las bases imaginarias de una nueva escritura, siendo uno de los fundadores de la modernidad en cuanto convirtió al signo poético en deseo exacerbado, en posibilidad de liberación y en lugar de encuentro de realidades antes insospechadas. Los cantos de Maldoror, además de ser el primer libro surrealista, es quizás una de las primeras manifestaciones de la escritura como caleidoscopía de sus propias posibilidades enunciativas. Pero más allá de un monumento erigido en Montevideo y a pocas cuadras del río que Ducasse convirtió en mar ("Yo te saludo, viejo océano," decía Maldoror, la influencia del más radical de los uruguayos ha sido casi inexistente en su país de origen. No tanto porque escribió en francés, sino más bien porque su escritura apuesta al fascinante riesgo de la dificultad y de la sexualización del universo, y en ese sentido los uruguayos han sido siempre fieles seguidores de la lógica cartesiana y excesivamente creyentes en los beneficios del pudor. La literatura de Lautréamont siempre fue vista como algo ajena y demasiado distante de los valores morales y de los gustos literarios de una nación cuya modernidad no pudo escapar de la intolerancia del positivismo. El aislamiento de Lautréamont, de todos modos, no es un caso aislado. Tampoco se justifica el olvido y el desconocimiento, tanto dentro como fuera de fronteras, de Julio Herrera y Reissig. Cuando la poesía hispanoamericana se agotaba de copiar los últimos estertores del modernismo, con un Darío que además de imitarse a sí mismo celebraba confusamente "la claridad del mensaje", Herrera y Reissig, exiliado en una húmeda buhardilla a pocas cuadras del puerto de Montevideo, 
rompía con todos los esquemas preconcebidos al inaugurar una lírica que ya anticipaba toda la artillería lingứística de la vanguardia. Con tres largos poemas, "La vida" y "Desolación absurda", de 1903, y "La torre de las esfinges", de 1909, Herrera incluye en la escenografía del poema todas las posibilidades de lo irracional, del furor erótico y de un mundo iconográfico irreferencial. Por primera vez en la literatura hispanoamericana el lenguaje habla de sí mismo. Estos tres poemas, casi ignorados por la crítica y excluidos repetidas veces de las antologías, son una síntesis anticipatoria de la práctica surrealista: escritura del inconsciente donde el cuerpo se expresa sin disimulos y la palabra resulta ser la única razón causal del Universo, el cual, para mayores detalles, no tiene causalidad. Sin embargo, el Herrera que el Uruguay conoce es el de los sonetos, el de la verbalidad menos subversiva, el más entendible. Como Lautréamont, Herrera y Reissig es un nombre que la historiografia literaria uruguaya - en caso de que la haya-reduce a ciertos datos de diccionario, pero que en última y en primera instancia no puede explicar ni relacionar con la literatura posterior. ${ }^{1}$ Estos ejemplos fundamentales prueban que el surrealismo en Uruguay existió antes de que existiera como tal, antes de que fuera un término aplicable a un movimiento o tendencia literaria. Los visionarios no tuvieron continuadores, salvo raros casos aislados que parecen confirmar la gran verdad de la literatura uruguaya: las excepciones nunca prueban la regla.

Para una crítica que veía a la poesía como un ejercicio de solemnidad y de información ideológica, era improbable que todo disparate cercano al surrealismo pudiera ser celebrado y promocionado como una opción completamente pertinente. $\mathrm{Y}$ como si el conformismo que la definía fuera poco, la crítica tuvo asimismo a su favor un aliado semanal. Desde principios de la década del cuarenta el mercado literario contó con otro elemento desestabilizante o, mejor dicho, neutralizante. La fundación Marcha en 1939 actualizó las ideas antiimperialistas de Rodó al impulsar la consagración de un ideario hispanoamericano y propiciar el rescate de un pensamiento vernáculo, más caracterizado por la vaguedad que por otra cosa. Vino a crear también un nuevo tipo de elitismo ideológico y artístico —además del oficialista que ya estaba en vigencia- del cual, incluso hasta el dra de hoy, gran parte de la literatura uruguaya no ha podido liberarse. El aura de un nacionalismo a ultranza que Marcha respaldó con insistencia más que con pluralismo, y que en nada contradecía la programática reformadora de laidentidad uruguaya iniciada por el absolutismo batllista, instauró una nueva clase de dogmatismo. La beatificación por parte del semanario de poetas menores - peroentendibles por todos- como Mario Benedetti y Líbero Falco, más que una puesta al día del lenguaje y una solución para el pasado de dependencia cultural como se

\footnotetext{
${ }^{1}$ Son ilustrativos de estos comentarios -evitando que los mismos puedan ser acusados de subjetividad-los libros de Angel Rama, Las máscaras democráticas del modernismo (Montevideo: Fiar, 1985) y de Emir Rodriguez Monegal, Literatura uruguaya del medio siglo (Montevideo: Alfa, 1966).
} 
pretendía, lo que trajo en verdad fue la presencia hipostática de un modelo anquilosado desde su inicio y carente de todo riesgo formal. La grisura, la idolatría del aburrimiento, la tristeza de los signos (sobre todo para un lector exigente) y el simplismo vinieron a sepultar definitivamente la audacia y el espíritu de aventura de toda una época. La crítica que trajo Marcha no fue "implacable" como todavía se vanaglorian algunos de sus defensores, sino parcialista y conservadora. Apostó a lo que se suponía era "la auténtica literatura uruguaya", haciendo culto a la solemnidad de una moral laica que dejaba a los disidentes sin otra salida que el solipsismo y la soledad. La opción era de intransigencia: o seguir el dictamen restrictivo de la publicación o escribir al margen de todo. El escritor Ariel Méndez (nacido en Rocha en 1919 y finalista en el Premio Biblioteca Breve de Seix Barral en 1964), un francotirador que nunca integró la lista de preferidos de la revista, comenta: "Marcha fue un antibiótico contra la locura. Lo que no entendian no lo publicaban". ${ }^{2}$ La observación de Méndez podría extenderse al espectro completo de la literatura uruguaya: todo lo que fuera difícil, todo lo que exigiera una participación lúdica de la imaginación, era sin mayor debate condenado a la indiferencia. La supuesta renovación acontecida en la poesía uruguaya en las décadas del cuarenta y del cincuenta fue un espejismo. El culto llevó al fanatismo y muchos llegaron a afirmar que Marcha sirvió pararenovar la literatura nacional. Quizás su fruto más conocido fue la llamada "generación del cuarenta y cinco", que activó el mercado editorial pero que poéticamente trajo autocondescendencia antes que innovación. El mismo año que Wittgenstein escribía, "si los hombres no cometieran algunas veces actos insensatos no ocurriría nada inteligente", toda una generación poética sin demasiado riesgo apostaba a la "sensatez" y al decoro de un tradicionalismo paralizado por su propia inflexibilidad intelectual. El semanario impulsó a los poetas de lenguaje evidente, a los que no iban más allá de la rutina de lo cotidiano, a aquellos que en su ortodoxia ideológica evitaban los ofrecimientos de lo irresoluto, de lo desconocido y del inconsciente en su más bello desorden. Por eso es que la brecha, al menos en poesía, nunca se abrió. Casi cien años antes otro uruguayo había advertido: "la misión de la poesía es difícil. Ella no se mezcla con los acontecimientos de la política, con la manera cómo se gobierna un pueblo, no hace alusión a los períodos históricos, a los golpes de Estado, a los regicidas, a las intrigas de cortes". ${ }^{3}$ Claro está que Marcha y sus seguidores, más interesados en "las intrigas de cortes", desoyeron el incuestionable vaticinio de Lautréaumont. La poesía, más bien, fue negada; la proclama y el fácil discurso de actualidad ocuparon su lugar. De esta manera, consideradas en conjunto las poco favorables condiciones para hacer efectiva la libertad de la imaginación, la poesía, no sólo la surrealista, resultaba en el

\footnotetext{
${ }^{2}$ Entrevista personal con Ariel Méndez llevada a cabo en Montevideo en julio de 1987.

3 "Isidore Ducasse, conde de Lautréamont", referido por Stefan Baciú en Surrealismo latinoamericano (Valparaíso: UCV, 1979), 110.
} 
Uruguay moderno una tarea insólita y heroica. Un acto caracterizado por su rareza. Y las rarezas no abundaron. Entre las pocas debe incluirse a los dos poetas que tradujeron en su lenguaje la experiencia surrealista: Álvaro Figueredo (1907-1966) y Selva Márquez (1899-1981). En 1956, el mismo año en que se publica en Buenos aires el tercer y -final- número de la revista $A$ partir de cero, dirigida por Aldo Pellegrini, que sería la última aventura editorial del primer grupo surrealista de Latinoamérica, Figueredo publica Mundo a la vez, su libro más personal y más afín a la aventura de recuperación de la imagen que el surrealismo venía proponiendo desde fines de la década del diez. ${ }^{4}$

Los tics y la reverberación de la ilogicidad surrealista emergen una y otra vez en este poemario, el cual, aunque carecía entre sus atributos fundantes de la suficiente energía verbal como para provocar el naufragio completo de la razón, arriesgaba al menos una discursividad removedora de los convencionalismos y del reduccionismo mecanicista del entendimiento. Más allá de su intermitencia, el rescate arqueológico del inconsciente deja salir a la superficie del texto una iconografía inédita.

alvarisimamente 0 extraviándome circularmente azul como un insecto como un rollo sin nombre blancamente como un plato de sopa atribulado como el roído eco.

Comentando las peculiaridades de su escritura, el poeta confiesa poner en juego "el inagotable repertorio que va de la imaginería barroca a la evasión surrealista", la que presumiblemente sería imperdonable para la crítica del momento, antes preocupada por loque se dioen llamar "literatura de compromiso" (por cierto nunca comprometida con el lenguaje) y detractora de toda actividad poética que pudiera promover una desesperación de irrealidad y un irresoluble conflicto de significados. Al respecto, también interesan sus comentarios relacionados al acto de la escritura, los cuales parecen ser un anticipo de las ideas de Roland Barthes que consideraban al texto literario como un espacio de productividad donde el signo, al no concluir su recorrido significante, favorece la condición inacabada del discurso. Dice Figueredo: "Aspiro a que el poema, más como un producto, logre consumarse, paradójicamente, como un producirse". ${ }^{\circ}$ Su poesía, precisamente, articula la insatisfacción del signo - que nunca llega a ser producto- mediante un orden inconclusivo donde la palabra está al

\footnotetext{
4 Es interesante observar que ni Figueredo ni Selva Márquez aparecen en el citado libro de Baciú, considerado por algunos como uno de los más importantes escritos sobre el surrealismo latinoamericano. El libro, que por cierto tiene muchas carencias conceptuales y antológicas, no hace ninguna mención a un posible surrealismo uruguayo.

${ }_{5}$ Álvaro Figueredo referido por Domingo L. Bordoli en Antología de la poesía uruguaya contemporánea (Montevideo: Universidad de la República, 1966), 34.
} 
servicio del ritmo y de un diálogo iconoclasta en busca de una imagen ideal y no del sentido. La ontología del poema es imaginaria y esta última palabra refiere a la posibilidad de conocimiento a partir de la fragmentación iconográfica. En cierta manera toda la práctica surrealista parte de una reinvención de las imágenes del mundo inmediato, no en un sentido impresionista de rescatar en el paisaje las formas de lo visual y convertirlas en postiza decoración, sino en tanto la imagen es un atisbo de síntesis de la complejidad de la percepción:

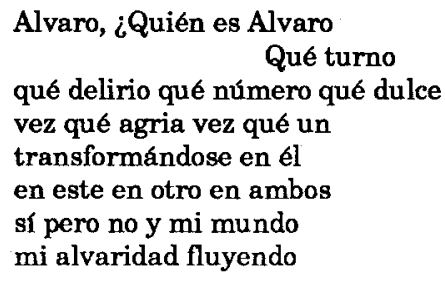

El problema fundamental de la lírica de Figueredo es la discontinuidad. Aunque momentáneamente -y algunos de estos momentos alcanzan el esplendor-su escritura acosa las posibilidades de multiplicación del erotismo metafórico, de la imagen, la misma no logra concentrar toda su carga elusiva en una retórica que se resuelva únicamente como fenomenología visual de la otredad. Entre el cúmulo de referencias que interrogan las contradictorias apariencia del universo, la palabra siempre está aludiendo a una certidumbre objetiva, a un punto de apoyo material; nunca llega a ser voz de sí misma. La iluminación surrealista, que pretendía hacer del lenguaje la única realidad necesaria, no se cumple del todo. La misma, no obstante, en tanto convicción por devolverle a la escritura su autotélica identidad, se cumplió de una manera más concluyente y personal en la lírica de otra casi desconocida. Selva Márquez es la voz de mayor intensidad surrealista que tuvo el Uruguay en los cuarenta años de auge del movimiento, entre 1920 y 1960, primero en Francia y después en Latinoamérica. Dos primeros libros donde su voz todavía no es reconocible, Viejo reloj de cuco y Dos, de 1936, y un tercero sorprendente, El gallo que gira, de 1941, hacen el total de su obra lírica. La suya, todavia no reconocida, fue la obra de un outsider. En medio de un lectorado que pretendía otras experiencias más permeables a la explicación del entendimiento racional, la lírica de Márquez, definida en su originalidad en El gallo que gira, aparece como un discurso descontextualizado. Su rareza comienza allí. A eso habrá que sumar la renuencia de la autora para publicar y la casi inaccesibilidad de su obra, nunca compendiada ni reeditada desde hace más de cincuenta años. El largo silencio que mantuvo la poeta ( $\mathrm{O}$ convendría llamarla "poetisa", por aquello de que la poeta tiene también algo de pitonisa?), desde 1941 hasta la fecha de su muerte, resulta al fin y al cabo un factor propiciante del desconocimiento de su poesía, sobre todo para un país donde la memoria no es el mejor de sus atributos. 
En esos cuarenta años Márquez no publicó ningún libro de poesía, apenas unos cuentos en revistas y una recopilación de éstos que salió póstumamente. En 1952 ganó el concurso de narraciones de la revista Asir con el cuento "El daimón de la casa López". En 1982, la editorial Arca publicó con ese mismo título un libro que recogía el cuento mencionado, además de otro ya conocido y de cuatro inéditos. El silencio auto-impuesto de Selva Márquez, que viene a coincidir en su hermetismo con el de Sor Juana y el de Rimbaud, agrega otro enigma a una lírica de por sí enigmática. Quienes la conocieron dan cuenta de que siguió escribiendo poesía y narraciones hasta el fin de su vida, pero desconocen la razón de su deseo (si es que el deseo se mueve por razones) de no publicar poesía después de 1941. Si los distintos testimonios son fidedignos, Márquez habria dejado una considerable obra poética inédita, pero se desconoce hasta la fecha si tal conjetura es verdad. Las interrogantes también se vuelcan a su lírica o, mejor dicho, de allí salen. ¿Es Selva Márquez en El gallo que gira una poeta surrealista? Sin duda, es una poesía difícil de encasillar según rígidas nomenclaturas taxonómicas. En la lírica de Márquez no se verifica un "surrealismo ortodoxo", en el sentido que la palabra no se abandona a una escritura automática; reconocidas sus varias trampas, el discurso permite confirmar una cuidadosa labor fictiva de reconstrucción y montaje. De todas maneras el lenguaje es surrealista por cuanto adquiere la sensibilidad incongruente del inconsciente y revalida su inconformismo ante el autoritarismo de la razón, ya como espejo de sí mismo, ya como finalidad sin fin. Así pues, la "inclasificable" anatomía de esta lírica ha llevado a recurrir a dos modalidades que han caracterizado a la crítica uruguaya, cuando de leer poesía se trata: la vaguedad (posiblemente por no poder traducir el desconcierto) y la simplificación (quizás producto de lo mismo).

Los juicios apresurados, que nunca parecen tener como referencia directa al propio texto, condujeron también a facilitar la contradicción, pues al mismo tiempo que "poeta social" Selva Márquez fue tenida como "poeta solipsista" cuyo lenguaje revela una inaccesible intimidad. Mientras que la guía Cien autores del Uruguay destaca el "yo de la poetisa" como una conciencia que revela, y el Diccionario de literatura uruguaya destaca su "línea confesional intimista", Sarah Bollo coincide con Domingo L. Bordoli afirmando que "Selva Máquez está muy lejos del sentimiento íntimo". ¿A quién creerle? Quizás en celebración de la heterogeneidad de los textos de Márquez, que propician lecturas diversas y hasta contradictorias, como los comentarios citados lo prueban, puede desprenderse que la lírica a consideración acepta ser leída como discurso social de temporalidad restringida que contradice los asedios de un ego omnisciente y a la misma vez se presenta como expresión hermética cuya referencialidad es

\footnotetext{
6 Diccionario de la literatura uruguaya (Arca: Montevideo, 1987); Cien autores del Uruguay, edición de Alejandro Paternain, Alberto Paganini y Gabriel Saad (Montevideo: Centro Editor de América Latina, 1969) y los libros citados de Bollo y Bordoli.
} 
dudosa o está diluida debajo de una escenografía figural proliferante. En ese paisaje de signos, cuya abundancia de sentidos inacabados recuerda a una jungla (¿la verdadera selva?), los varios elementos de la iconografia surrealista abundan. ¿Cómo caracterizar entonces el surrealismo de Márquez? Además de ser desconocida, la personalidad de la poeta (su yo social), puede ser un obstáculo en la travesía hacia la interpretación. Las respuestas deben venir del lenguaje, tal vez el único lugar donde los enigmas y las repuestas de significancia (en caso de haberlas) podrian encontrarse. En su notable libro Filosofía del surrealismo, Ferdinand Alquié recuerda que la "conciencia surrealista no se ofrece como conciencia de una verdad conceptual o de valor moral trascendente". ${ }^{7}$ La misma más bien se presenta como lenguaje, como total expansión de éste, para identificarlo con el hombre y con los alcances de su libertad. La evidencia de ese lenguaje alcanza su realización en la elusividad de las imágenes. La poesía surrealista impulsa una reversión de la imagen vista como gran sospecha de la otredad del mundo: de ella parte y de ella se nutre la palabra. Su realidad (verdadera surrealidad), comienza como una implosión de lo imaginario: presentimiento de un espacio reconciliador donde se cumple la afectividad de las cosas, el sentimiento de la materia que posibilita las formas del universo. No de otro lugar sino de allí parte también la lírica de Selva Márquez: matriz de lo visual, que es tanto principio de una realidad despierta como de la vigilia de la lectura. Queda claro pues - por más que la lírica a estudio de claro tenga muy poco-, que la poesía de Márquez, en su devenir hacia una visualidad sin referente, regresa al estado original de la imagen, a esa zona de transrealidad donde lo imposible y lo verídico se comunican:

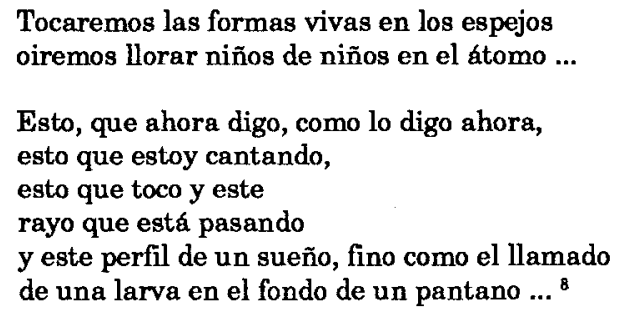

En su irreverencia y exigencia de un registro de asignificancia, El gallo que gira es una apertura surrealista a la autodeterminación del lenguaje. Inaugura un espacio de intercambio enunciativo donde lo comunicable y lo incomunicable dejan de ser percibidos contradictoriamente y donde el pensamiento de la escritura combina un amplio espectro de posibles estrategias asociativas de

\footnotetext{
${ }^{7}$ Ferdinand Alquié, Filosofia del surrealismo (Barcelona: Seix Barral, 1974), 182.

${ }^{8}$ Selva Márquez, El gallo que gira (Montevideo, 1941, sin mención de editor), 36.
} 
elementos en apariencia antinómicos entre si, para resolver en el recorrido impredecible de la palabra la expresión más reciente de la belleza, esa puesta al día del hombre anhelada por el surrealismo. La pulsión torrencial de la escritura de Márquez genera una multiplicidad de congruencias en la economía verbal, que bien parece un viaje a lo esencial de la poesía: su pluralidad. El contrapunto entre lo uno y lo distinto y la textura caleidoscópica que resulta de la oposición de los contrarios, subrayan el carácter inestable del significado y justifican su desdoblamiento en un ciclo de rechazo y aceptación de toda lectura interpretativa: el absurdo también emerge frustrando una elucidación unitiva del texto:

\author{
Cuando llora \\ una serpiente \\ rompe la elipse hermética del huevo \\ y presta a Odio un nuevo diente (46).
}

La palabra sigue una trayectoria desestabilizante y en su indecibilidad aniquila la posibilidad de convertirse en un instrumento de la razón. Su nombrar invalida una coincidencia especular. Por eso puede hablarse de un regreso a la intimidad del signo: el escenario se cubre de imágenes (quizás la mejor prueba del mundo), pero en ese paisaje que apela a la fascinación de lo visual la escritura se pliega sobre su propia geografía y al lograrlo alcanza su exuberancia en un espacio de autorreferencialidad, tan imaginario como la sustancia discursiva que lo contiene. Sueño y realidad, imaginación y memoria, coincidencias y oposiciones, se intercambian sin ninguna dependencia lógica en el recinto del poema:

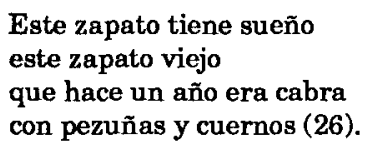

Los dispositivos disgregacionales cuentan con apoyo: la total ausencia de un eje narrativo (o emotivo) apresura el desenlace de "dificultades" que distinguen el diseño conflictivo de esta lírica, donde lo real y lo maravilloso, en espléndida comunión surrealista, se dan idénticos. Poética de la desmaterialización, que sin llegar a la pura disolución de la idea, se desprende de todo encauce lógico para devolver los sentidos y la sensualidad al mundoirresoluble de las cosas. En este intercambio de alternativas de persuasión, la discursividad, aunque sigue un recorrido heteronominativo - y esta palabra es la más adecuada para aludir al comportamiento desviacional de los textos - no queda exenta de orden ni de simetría, por más que el logos racional siempre sea cuestionado por la discontinuidad que desborda el abanico semántico. El ritmo de la palabra es interruptivo pero no cancela la posibilidad de interpretación (la atomiza): por 
eso se habla de lenguaje surrealista y no de surrealismo en el sentido de completa disposición y entrega a las reverberaciones del inconsciente. En esta poética, como se dijo, la complejidad del signo deriva de una concertada práctica fictiva, cuyo insistir traduce la lógica del azar en artificio de precisión. El destino impremeditado de las situaciones enunciativas, la plétora de soluciones de sentido y la prevalencia lúdica que irradian las combinaciones metafóricas establecen un intersticio textual ilusorio cuya única referencia está en el fluir incesante y reversivo de la escritura, en las paradojas formales de ésta. Volumen sin peso, representación de la inmaterialidad de la materia, el poema logra su intensidad en lo no probable, en aquello que de otra manera no podría existir como destino final del lenguaje:

La tarde, jadeante, está abierta a la embestida del sagrado Toro que en el círculo hermético rueda: Otoño (44).

La formación utópica del lenguaje, en su insistencia de hermeticidad, se aparta de la función utilitarista del discurso. A la palabra instrumental que enuncia la fracción colectiva del lenguaje, la lírica de Márquez opone la palabra poética, definida por su entropía disociativa. En las elipsis retóricas donde la realidad se muestra inverificable, las apariencias de ésta quedan designadas por una figura impropia que, sin imposibilitar la representación, altera el juego de las correspondencias pues el lenguaje es el lugar de los fenómenos, no de las cosas. La lírica de Márquez (razón que guía lo fortuito), revela en el horizonte del significado una figura anagramatical que privilegia la forma de la palabra como su única manera de ser y que opone la diversidad verbal sobre la cosa significada. El mundo no se verifica en la palabra: su autenticidad está degradada, en cuanto el lenguaje es el que tiene la inciativa. Su exuberancia lleva a la abstractividad musical, al vacío del sentido o, mejor dicho, a un sentido puramente visual y sonoro:

Ay! Helada Artemisa de las encrucijadas, lengua de lija y leche de los higos malditos! Ay! Perra trashumante babeando lupanares y bodas, comuniones y muertes y bautizos!

Sexo de las estatuas, mirada de pescado hacia Ti vamos todos caminando despacio (13).

La decisión de establecer una nueva comunicación poética es evidente, puesto que el discurso en la totalidad de su recorrido evita el utilitarismo de la palabra (con toda su trama de referencias convencionales) para devolverle a ésta, (ya completamente actualizada y despojada de todo artificio de explicitud) una pureza inventiva que facilite la presencia en el mismo ámbito de los 
contrarios sin contradicción. De esta manera, en el lenguaje se realiza el desafío de la productividad: la experiencia del texto reproduce la autosuficiencia de las distintas estrategias metaforológicas para llevar el significado al límite de su expresividad: la representación de la palabra como entidad autónoma es en verdad representación del orden imaginario del universo. Es también la prueba de la profunda incompletitud de su funcionamiento real. El texto distrae pero no reproduce: se establece como una intencionalidad sin causa y por lo tanto su sentido es residual. Como apoyo a la disociación, la metáfora amplía y omite. El traslado de un significante a otro es arbitrario, ya que la relación entre el referente y lo referido está interiorizada y no responde a razones causales:

\author{
$\mathrm{Y}$ en el instante de una luz \\ mi corazón supo \\ por qué la lengua de Antares \\ lame el vientre de la foca! (17).
}

La palabra, como se lee en los ejemplos que se han ido sucediendo, presenta irreconocibles a los objetos que refiere. En tanto se excluye la posibilidad de identificación y se corrobora el carácter irreductible de la metáfora, el poema funciona siempre en la periferia de lo probable. Es la verdad práctica de la imagen: su eficacia es inmediata ya que la plenitud de lo visual actúa como mediadora de un conocimiento perceptivo que ha superado en su apertura fenomenológica las interferencias y limitaciones del entendimiento lógico deductivo. En el filtro escriturario conformado (aunque su inconformismo es evidente) por la heterogeneidad de la realidad y de lo imaginario, la percepción experimenta - una vez superado el cerco racional - la transparencia absoluta de los objetos. La exploración lingüística devuelve al poema la imagen de los objetos transformada: su tangibilidad es sensorial, su existencia es inverificable. Dado a su propio flujo, el lenguaje es atravesado por las cosas, pues allí -en el cedazo retórico- es donde éstas comienzan a existir y no antes. En la realización unitiva de las palabras con los acontecimientos (tanto perceptivos como materiales) podrá entonces constatarse el "azar objetivo" que los surrealistas tenían como modalidad definitoria para conocer el sentido oculto de la realidad. La poesía de Selva Márquez es así la mejor aclimatación, no sólo por ser la única, del surrealismo en la literatura uruguaya. Esta no es mimética ni sigue la ortodoxia bretoniana, sino que está recreada en un mestizaje lingüístico donde se presencia una flexibilidad para dar cabida a expresiones localistas junto a ciertas líneas de surrealidad diferenciantes cuya actualidad queda resuelta en la poética de lo fragmentario:

Las palabras son abejas muertas cuando lloran las nubes

y cuando crecen cicutas y hortigas y florecen los árboles de ahorcados (47). 
El lenguaje no se cumple en el significado ni en la coincidencia de los elementos relacionables de una narratividad sino en la discontinua dicción arbitraria de sus resoluciones, las cuales se remontan a la prehistoria del sentido y tienen como origen la inconformidad de la imaginación y de sus posibles representaciones persuasivas. El inconformismo lleva al aislamiento del ser, del signo y de todo loque acontece. Breton destacaba que "el surrealismo únicamente podrá explicar el estado de completo aislamiento al que esperamos llegar, aquí, en esta vida". ${ }^{9}$ La prueba del aislamiento en la lírica de Selva Márquez se cumple mediante un abandono al fluir del discurso y a su continua recurrencia a la otredad, a la que nunca deja de ser distinto pues siempre viene a mostrarse como múltiple visualidad en el espejo alucinatorio de la imagen. Las estrategias que la poeta utiliza para hacer efectivo este distanciamiento son

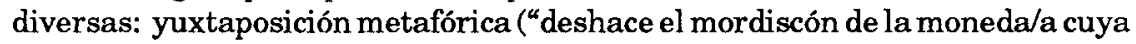
sombra espesa nacen hongos", 8); experiencia sinestésica de la realidad objetiva ("El metal del anillo sueña fuegos en mares,/abrazado a las aguas convertidas en aire", 34); discontinuidad de sentido en la misma serie metonímica ("y el de la risa oscura de la taba,/y el cascado rodar/de los amores con taxímetron, 7); y pensamiento analógico que excede la causalidad ("y este perfil de un sueño, fino como el llamado/de una larva en el fondo de un pantano ...” 36). En su traza itinerante, la lírica de Márquez rescata la transindividualidad del lenguaje. En la palabra, el Ser es uno y universo: allí recupera la intensidad del origen. La escritura es sorpresa, la belleza llama al asombro perpetuo: es la celebración del encuentro fortuito de un paraguas y una máquina de coser. En la fusión de todas las cosas, incluso las más ajenas unas con otras, comienza la inesperada resolución de la realidad. Lautrémont, y con él la imaginación, es reivindicado. La densidad de las palabras toma el camino de la seducción: lo imaginario se muestra de la manera más intensa. Su intensidad (sin soluciones), acepta el traspaso de las formas del mundo real al espacio del discurso y el pasaje del didactismo objetivo - que caracterizaba a la poesia uruguaya en las décadas del cuarenta y del cincuenta - a la inverosimilitud de una palabra definida únicamente por su significancia, por su sensualidad y por su lúdica simulación. El enfasis se traslada a una belleza hierática y compleja que arriesga absolutamente todo en la cancelación del sentido y que no descarta de su itinerario la impenetrabilidad y la posibilidad de irresolución. Después de todo, el verdadero contexto de la escritura poética debe ser la forma del texto. Allí precisamente reside la lírica de Márquez: poesía que vive de la poesía, registro de una letra asignificativa que se nutre de su propia heterodoxia. No obstante, como debía suponerse, esta escandalosa reivindicación de la elusividad fue ignorada. El novelista inglés antirromántico Thomas Love Peacock señaló tiempo atrás que "un poeta en nuestro tiempo es un 'semibárbaro' dentro de una

${ }^{9}$ Andre Breton, Manifiestos del surrealismo (Madrid: Guadarrama, 1985), 69. 
comunidad civilizada". El comentario, que viene a resaltar la poca compensación que la espontaneidad ha tenido en la época moderna, encuentra un buen punto de referencia en la literatura uruguaya. El Uruguay, que con todas sus fuerzas sociales (incluidos los críticos literarios y los semanarios informativos) apostó a ser un modelo de civilización, rechazó o ignoró a priori las manifestaciones de disidencia. La extravagancia, como en el caso de Selva Márquez, fue imperdonable. La silenciosa subversión de la palabra poética podía llevar al exceso y a la consagración del caos. La originalidad y el uso de la imaginación resultaban prácticas peligrosas. La originalidad venía a significar el regreso al origen, a un estado irracional carente de cualquier tipo de atributos. La imaginación, por su parte, llevaba a la voluptuosidad del desorden, a la semibarbarie, a una escritura incomprensible sin ninguna función social. No había otra alternativa: el "estado modelo" debía prevalecer por encima de todo. Los poetas, otra vez, debían quedar fuera de la República. 
